\title{
Dificuldades e obstáculos apresentados por um grupo de professores de Matemática no estudo da geometria hiperbólica
}

\author{
Karla Aparecida Lovis', Valdeni Soliani Franco ${ }^{2}$, Rui Marcos de Oliveira Barros ${ }^{3}$
}

Resumo: O objetivo deste artigo é descrever as dificuldades e os obstáculos apresentados por um grupo de professores de Matemática da Educação Básica observados durante um minicurso introdutório sobre a Geometria Hiperbólica. Os sujeitos da pesquisa são quarenta e um professores de Matemática de cidades da região norte do estado do Paraná. Para obter os dados da pesquisa, realizou-se um minicurso sobre a Geometria Hiperbólica, especificamente o Modelo de Poincaré, e o GeoGebra, no qual foram gravadas, em áudio e vídeo, as falas dos professores e as atividades por eles realizadas. Da análise, destaca-se que as dificuldades e os obstáculos para a compreensão de conceitos básicos da Geometria Hiperbólica estão relacionados à representação dos objetos geométricos nesta Geometria, bem como à "contaminação" que a Geometria Euclidiana desempenha no momento do aprendizado da Geometria Hiperbólica. Observou-se também dois obstáculos epistemológicos: geral e verbal. Palavras-chave: Ensino de Geometrias; Geometria Hiperbólica; Dificuldades e Obstáculos Epistemológicos.

\section{Difficulties and barriers presented by a group of Math teachers in the study of Hyperbolic Geometry}

Abstract: The aim of this article is to describe the difficulties and barriers presented by a group

\footnotetext{
1 Doutora em Educação para a Ciência e a Matemática - Pós-Graduação em Ciências e Matemática da Universidade Estadual de Maringá - PCM/UEM. Instituto Federal Catarinense - IFC - Câmpus Concórdia. karla.lovis@ifc-concordia.edu.br

2 Doutor em Matemática pelo Instituto de Ciências Matemáticas e de Computaçãoda Universidade de São Paulo - ICMC/USP - São Carlos. Universidade Estadual de Maringá. vsfranco@uem.br

${ }^{3}$ Doutor em Matemática pelo ICMC/USP - São Carlos. Universidade Estadual de Maringá. professorrui@hotmail.com
} 
of Junior School Math teachers during an introductory course on Hyperbolic Geometry. Fortyone Math teachers participated in this research, from cities in the northern region of the state of Paraná, Brazil. A mini-course was taught about Hyperbolic Geometry, specifically on Poincaré's Model and GeoGebra, to obtain data for current research. Teachers' discourses and activities were recorded for this purpose. From this analysis, it must be highlighted that difficulties and barriers to comprehend basic concepts of Hyperbolic Geometry are related to the representations of geometrical objects in this type of Geometry, as well as to the 'contamination' that Euclidean Geometry provides on learning Hyperbolic Geometry. It was also observed two epistemological barriers: general and verbal.

Key words: Geometry Teaching; Hyperbolic Geometry; Epistemological barriers and constraints.

\section{Introdução}

A problemática desta investigação surgiu devido à inclusão do tópico "geometrias não-euclidianas" nas Diretrizes Curriculares de Matemática (DCE) do estado do Paraná. No ano de 2008, a Secretaria de Educação (SEED) publicou o documento com a inclusão de cinco Geometrias: Geometria Projetiva, Topologia, Geometria Fractal, Geometria Hiperbólica e Geometria Elíptica ${ }^{5}$.

As DCE recomendam que os conteúdos de Geometrias não Euclidianas devem ser ensinados nos Ensinos Fundamental e Médio. No Ensino Fundamental, o aluno deve ser capaz de compreender noções da Geometria Projetiva, de Topologia e da Geometria dos Fractais. No Ensino Médio, deve aprofundar o estudo da Geometria dos Fractais e ser introduzido à Geometria Hiperbólica e à Geometria da Superfície da Esfera. Sobre a Geometria Hiperbólica, as DCE recomendam: "para abordar os conceitos elementares da Geometria Hiperbólica, uma possibilidade é através do postulado de Lobachevsky (partindo do conceito de pseudo-esfera, pontos ideais, triângulo hiperbólico e a soma de seus ângulos internos)" (Paraná, 2008, p. 57).

Diante da inclusão da Geometria Hiperbólica e das recomendações da

\footnotetext{
${ }^{4}$ Nas DCE, a palavra “não-euclidianas" é escrita com hífen. No decorrer deste trabalho, no entanto, será usada sem hífen.

${ }^{5}$ Nas DCE, a Geometria da Superfície Esférica é chamada de Geometria Elíptica. Porém, ao descrever essa Geometria, percebe-se que as diretrizes se referem, na verdade, à Geometria da Superfície Esférica, construída por Riemann. A Geometria Elíptica foi desenvolvida por Félix Klein. Um de seus modelos é obtido por meio da identificação dos pontos antípodas da Superfície Esférica, gerando o que se denomina de Plano Projetivo. Nesta Geometria, o primeiro postulado de Euclides é verificado, o que não ocorre na Geometria da Superfície Esférica.
} 
DCE, foi proposto o minicurso - O Modelo de Poincaré e o GeoGebra - com duração de 24 horas, para professores que atuam nas escolas públicas do Núcleo Regional de Educação - NRE - de Maringá. Os 41 professores de Matemática participantes do minicurso foram convidados pelo NRE. O objetivo foi introduzir alguns conceitos e resultados da Geometria Hiperbólica, especificamente do modelo de Poincaré, por meio do software GeoGebra. Durante o minicurso, investigaram-se as dificuldades e os obstáculos que os participantes apresentam no estudo da Geometria Hiperbólica. Os dados da pesquisa foram obtidos por meio da gravação - em áudio e vídeo - da observação e da aplicação de um questionário.

No decorrer do artigo, destacam-se algumas considerações históricas, filosóficas e matemáticas da Geometria Euclidiana e da Geometria Hiperbólica. Por fim, apresentam-se as análises das falas dos professores, com o intuito de identificar as dificuldades e os obstáculos epistemológicos.

\section{Considerações sobre a Geometria Euclidiana e a Geometria Hiperbólica}

Autores como Eves (1992) e Gerdes (1992) destacam que foi por meio de observações da natureza que se chegou à noção de lei ou regra geométrica. Com isso, a Geometria passou de uma ciência empírica para uma ciência matemática, na qual foi possível demonstrar proposições e abstrair resultados.

A origem da Geometria Euclidiana está, de certa forma, associada ao desenvolvimento das civilizações babilônica, egípcia e grega. Essas três civilizações contribuíram, de modo significativo, para a elaboração do conhecimento geométrico. Em geral, os babilônicos e os egípcios desenvolveram uma Geometria mais prática, com o objetivo de responder aos problemas com os quais se deparavam.

Para Barker (1969), a civilização grega, ao contrário dos babilônicos e dos egípcios, apreciava a Geometria não apenas em virtude de suas aplicações práticas, mas em virtude de seu interesse teórico.

Gálvez (2006) expõe que o momento culminante da Geometria Euclidiana aconteceu quando Euclides escreveu a obra Elementos (aproximadamente 300 anos a.C.), na qual sintetizou o saber geométrico da sua época. A obra é composta de 13 livros, nos quais ele apresentou 121 definições, 5 postulados geométricos e 5 noções comuns; e demonstrou 465 teoremas. Os 13 livros versam sobre Geometria Euclidiana Plana e Espacial, teorias dos números e grandezas incomensuráveis. Nos seis primeiros livros, há os

$$
\text { Zetetiké - FE/Unicamp - v. 22, n. } 42 \text { - jul/dez-2014 }
$$


conteúdos de Geometria Plana e, nos livros XI, XII, XIII, a Geometria Espacial (Souza, 1948). Os postulados de Euclides (2009, p. 98) são: 
1. Fique postulado traçar uma reta a partir de todo ponto até todo ponto.

2. Também prolongar uma reta limitada, continuamente, sobre uma reta.

3. E, como todo centro e distância, descreve um círculo.

4. E serem iguais entre si todos os ângulos retos.

5. E, caso uma reta, caindo sobre duas retas, faça os ângulos interiores e do mesmo lado menores do que dois retos, sendo prolongadas as duas retas, ilimitadamente, encontrarem-se no lado no qual estão os menores do que dois retos.

Barker aponta que as ideias adotadas por Euclides nesses postulados diferem muito das concepções indutivas e empíricas adotadas pelos egípcios. Nos três primeiros postulados, Euclides não está, de maneira direta, discutindo problemas de medição de terras; também não está preocupado com os possíveis obstáculos (montanhas, rios ou outros) que possam impedir seu traçado. As condições práticas não interessavam a Euclides; ou, em outras palavras, ele admitia existir "um espaço em que inexistiam obstáculos absolutos e em volta do qual inexistiam fronteiras exteriores absolutas" (Barker, 1969, p. 31). O quarto postulado parece um tanto evidente, mas Euclides o descreve como uma verdade lógica, uma vez que ele foi utilizado em diversas demonstrações na sua obra.

Quanto ao quinto postulado, observa-se que ele não é tão evidente quanto os quatro primeiros. Na Figura 1, se a soma dos ângulos internos $\alpha+\beta$ $<180^{\circ}$, as retas s e r irão se encontrar; se a soma dos ângulos internos $\alpha+\beta=$ $180^{\circ}$, as retas s e r serão paralelas.

Figura 1 - Esboço do quinto postulado

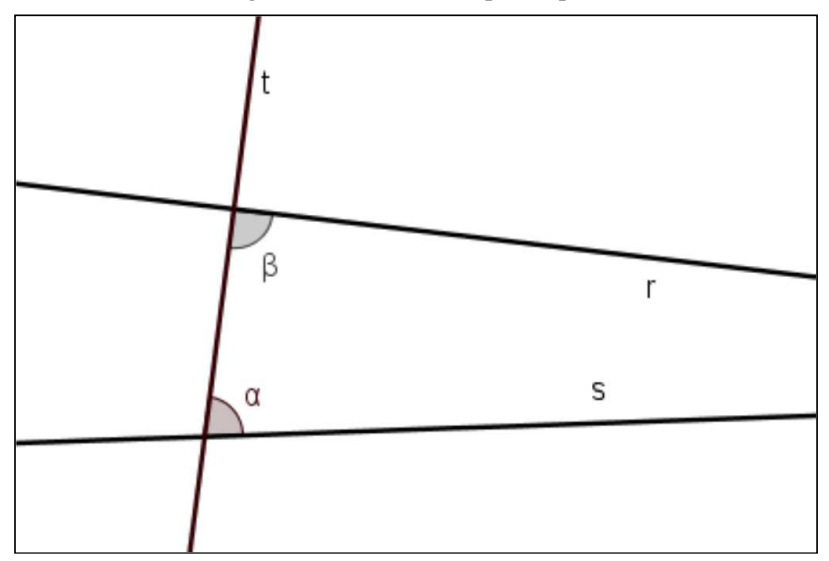

Zetetiké - FE/Unicamp - v. 22, n. 42 - jul/dez-2014 
Fonte: Autores deste texto

Os postulados, os axiomas e as definições são o ponto de partida das demonstrações de Euclides tanto da Geometria Plana quanto da Espacial. Barker (1969, p. 38) destaca que "Euclides, nos Elementos, visava a aperfeiçoar o nosso conhecimento acerca de pontos, linhas e figuras, tornando mais rigorosas as demonstrações de leis já conhecidas, e visava a aumentar esse conhecimento, demonstrando leis novas, até então desconhecidas". Euclides ofereceu à Geometria uma forma dedutiva sistemática, para que as demonstrações fossem mais rigorosas e possibilitassem a elaboração de novas leis. Piaget e Garcia (1987, p. 91) destacam que

$$
\begin{aligned}
& \text { [...] a geometria é, nas matemáticas gregas, o ramo que deu prova } \\
& \text { de uma tal perfeição que se transformou, durante vários séculos, } \\
& \text { no próprio paradigma da ciência. Dois mil anos após Euclides, } \\
& \text { ela será para Newton o modelo para toda a construção de uma } \\
& \text { teoria científica e os seus Principia inspirar-se-ão neste modelo. }
\end{aligned}
$$

Um momento fundamental no desenvolvimento dos conceitos geométricos aconteceu com a construção das Geometrias não Euclidianas. Durante muitos séculos, houve a preocupação em questionar a veracidade do quinto postulado (postulado das paralelas), inclusive chegou-se a pensar que não se tratasse de um postulado, mas de um teorema.

Foi no final do século XIX que os matemáticos compreenderam a situação lógica do quinto postulado e afirmaram que ele é independente dos outros postulados de Euclides, ou seja, que é possível existirem sistemas geométricos consistentes, nos quais o quinto postulado pode ser substituído por uma afirmação contrária. Uma das maneiras de negar o quinto postulado é afirmar que, por um ponto fora de uma reta, é possível traçar pelo menos duas retas paralelas, o que acontece na Geometria Hiperbólica. Outra maneira de negar o quinto postulado é afirmar a não existência de retas paralelas, que ocorre na Geometria da Superfície da Esfera.

Poincaré (2008) destaca que o desenvolvimento da Geometria Hiperbólica surgiu como algo revolucionário, uma vez que vários filósofos, matemáticos e pensadores de épocas passadas haviam afirmado que só existia uma Geometria verdadeira, a Geometria de Euclides. Ainda segundo o autor,

[...] depois dos gritos escandalizados, habituamo-nos ao que elas têm de paradoxal; várias pessoas chegaram até a duvidar do postulado, a se perguntar se o espaço real é plano, como supunha Euclides, ou se apresenta uma ligeira curvatura. Chegaram 
mesmo a achar que a experiência poderia dar-lhes uma resposta a essa pergunta. É desnecessário acrescentar que isso equivaleria a desconhecer completamente a natureza da geometria, que não é uma ciência experimental (Poincaré, 2008, p. 110).

O desenvolvimento de outras Geometrias, que contradizem o quinto postulado de Euclides, não quer dizer que a Geometria Euclidiana não seja verdadeira, e, sim, que todas são verdadeiras e possuem um sistema lógico consistente.

\section{A noção de obstáculo epistemológico}

Para Gaston Bachelard (1996), a ciência evoluiu de forma não linear. O autor destaca que as sucessivas mudanças ocorreram por meio de erros, descontinuidade, rupturas e contradições. Ao iniciar a sua obra $A$ formação do espirito cientifico, Bachelard (1996, p. 17) aponta:

[...] quando se procuram as condições psicológicas do progresso da ciência, logo se chega à convicção de que é em termos de obstáculos que o problema do conhecimento científico deve ser colocado [...] é no âmago do próprio ato de conhecer que aparecem, por uma espécie de imperativo funcional, lentidões e conflitos. É aí que mostraremos causas de estagnação e até de regressão, detectaremos causas de inércia às quais daremos o nome de obstáculos epistemológicos.

Andrade (2004, p. 47) destaca que a expressão "obstáculo epistemológico" foi criada "para caracterizar tudo aquilo que obstrui, impede, dificulta, enfim, limita o progresso da ciência, e podem ser citados como exemplos, o pré-conceito, a ideologia, a idolatria, o senso comum e a opinião".

$\mathrm{Na}$ busca pelo conhecimento científico, muitas vezes, os cientistas se deparam com obstáculos que podem dificultar o progresso da ciência e o entendimento de teorias. O aparecimento dos obstáculos epistemológicos é algo difícil de ser evitado, visto que o conhecimento científico não é alcançado sem que indagações, refutações e críticas sejam feitas.

Bachelard (1996, p. 18) destaca que, para o pensamento científico se desenvolver, é necessário que esses obstáculos sejam superados. O primeiro deles é a opinião: "a opinião pensa mal; não pensa: traduz necessidades em conhecimento [...] não se pode basear nada na opinião: antes de tudo, é preciso destruí-la. Ela é o primeiro obstáculo a ser superado". Afirma o autor que a atividade científica não deve ser baseada nas experiências comuns e na opinião. Para produzir conhecimento científico, o cientista deve estabelecer um vínculo 
entre a observação e a experimentação, questionando e discutindo as ideias que são apresentadas. Ainda segundo Bachelard (1996), os erros ocorridos no decorrer da evolução das ciências podem ajudar a detectar vários obstáculos epistemológicos que surgiram ao longo da história.

Outro obstáculo apontado por Bachelard (1996, p. 29) é a experiência primeira: "a experiência colocada antes e acima da crítica - crítica esta que é, necessariamente, elemento integrante do espírito científico". Para o autor, a experiência primeira deslumbra, porque dá preferência mais às imagens do que às ideias, ela é livre de qualquer espécie de crítica, de refutação e não constitui uma forma segura, nítida e clara que possa contribuir para a formação e o fortalecimento do conhecimento. Bachelard (1996, p. 14) destaca ainda que "a experiência comum não é de fato construída; no máximo é feita de observações justapostas [...] como a experiência comum não é construída, não poderá ser, achamos nós, efetivamente verificada. Ela permanece um fato".

Assim, a análise dos obstáculos no contexto da Matemática deve ser realizada com uma atenção especial, porque, segundo Bachelard (1996), esta ciência apresentaria uma regularidade no seu desenvolvimento, com períodos de paradas, mas não de erros ou rupturas. De fato, as rupturas encontradas na evolução das ciências experimentais não aparecem com clareza nos registros históricos da Matemática, por exemplo. Porém, isso não quer dizer que, em se tratando da Matemática, exista uma linearidade absoluta na fase da descoberta e do desenvolvimento desta ciência. Uma demonstração envolve um processo de criação; no entanto, não revela os intensos conflitos na criação dos conhecimentos.

Trovon (2012, p. 2) destaca que os textos matemáticos, tais como são apresentados à comunidade científica, passam por um processo de redação traduzido pelas demonstrações e por toda a forma valorizada pelos paradigmas da área. Para o autor,

[...] no caso da matemática, os obstáculos aparecem com mais intensidade na fase da aprendizagem e síntese do conhecimento, do que em seu registro histórico [...] os avanços, retrocessos, dúvidas e erros cometidos na etapa em que as conjecturas são feitas pelo matemático, praticamente, desaparecem no resultado final apresentado pelo texto científico. Por outro lado, esses conflitos sinalizam possíveis obstáculos, mas, como a história da matemática se baseia essencialmente nos registros textuais, pode transparecer que, no transcorrer de sua descoberta, haja uma aparente regularidade (Trovon, 2012, p. 2).

Zetetiké - FE/Unicamp - v. 22, n. 42 - jul/dez-2014 
Dessa forma, na Matemática, os obstáculos aparecem com maior intensidade na fase de criação dos conceitos, o que, normalmente, não se revela na redação final do texto matemático. Durante o processo de ensino e aprendizagem, no contato com um conceito novo, podem ocorrer. Bachelard (1996) expõe que é preciso superar esses conflitos para que o novo conceito possa ser aprendido. Também defende a necessidade de romper com o saber do senso comum.

No que se refere ao conhecimento geométrico, Santos (2009) destaca que é comum encontrar professores que se baseiam em experiências e em observações para descrever a Geometria Euclidiana. A autora observou que, para muitos professores, o plano euclidiano é visualizado no mundo físico e afirma que "parte do mundo onde vivemos é plano" (Santos, 2009, p. 96). Nesse contexto, é comum encontrar professores que buscam alicerces em experiências e em observações para descrever um conhecimento geométrico. É possível representar um plano euclidiano por um tampo de uma mesa, por exemplo, mas deve-se deixar claro que esse objeto somente representa parte de um plano euclidiano, e o tampo da mesa não é, de fato, um plano euclidiano. Nesses casos, conclusões indevidas, oriundas da experiência ou de uma simples observação, podem interferir no entendimento dos conhecimentos científicos e constituir-se, assim, obstáculos epistemológicos.

O conhecimento geral também foi considerado por Bachelard (1996, p. 69) um obstáculo ao conhecimento científico: "nada prejudicou tanto o progresso do conhecimento científico quanto a falsa doutrina do geral, que dominou de Aristóteles a Bacon, inclusive, e que continua sendo, para muitos, uma doutrina fundamental do saber". Para o autor, as generalizações podem, muitas vezes, falsear a realidade, comprometendo a veracidade das informações. Frases prontas que expressam uma generalização falseada são mais simples de difundir, mas elas acabam fazendo retroceder o conhecimento científico e, muitas vezes, são tidas como verdades absolutas. Bachelard (1996, p. 70) acrescenta algumas generalizações do pensamento científico:

[...] como fundamento da mecânica: todos os corpos caem. Como fundamento da óptica: todos os raios luminosos se propagam em linha reta. Como fundamento da biologia: todos os seres vivos são mortais. Seriam assim colocadas, no limiar de cada ciência, grandes verdades primeiras, definições intocáveis que esclarecem toda doutrina.

No contexto desta pesquisa, algumas afirmações da Geometria 
Euclidiana podem ser consideradas generalizações e consistir em obstáculos gerais, principalmente para o entendimento das Geometrias não Euclidianas. Citem-se exemplos como estes, dentre outros: a soma dos ângulos internos de um triângulo é sempre $180^{\circ}$; dada uma reta $r$ e um ponto $\mathrm{P}$ fora dessa reta, existe somente uma reta que passa por P e é paralela a r; a distância entre duas retas paralelas é constante. Tais afirmações são verdadeiras, desde que se esteja trabalhando com a Geometria Euclidiana. Diante disso, é preciso especificar claramente para o professor/aluno de qual Geometria se fala, para que essas afirmações não sejam apresentadas como "resultados intocáveis", "grandes verdades primeiras" que representam as veracidades do conhecimento geométrico.

Bachelard (1996, p. 91) descreve ainda o obstáculo verbal, ou seja, "um caso em que uma única imagem, ou até uma única palavra, constitui toda a explicação". Em se tratando das Geometrias, é complicado ensinar esses conteúdos sem utilizar as figuras geométricas. Mas o que deve ficar claro para o professor/aluno é que a figura geométrica representa apenas uma instância física da representação do objeto. Para Bachelard (1996, p. 48), uma imagem pode constituir um obstáculo verbal: "uma ciência que aceita as imagens é, mais que qualquer outra, vítima das metáforas. Por isso, o espírito científico deve lutar sempre contra as imagens, contra analogias, contra metáforas".

Quando da representação de uma reta paralela passando por um ponto, na Geometria Euclidiana, obtém-se a existência de uma única reta paralela. $\mathrm{Na}$ Geometria Hiperbólica, ao representar uma reta paralela passando por um ponto, podem-se obter infinitas retas paralelas que passam por esse ponto. As representações de retas paralelas nesses dois modelos são distintas. Porém, o conceito de reta paralela é o mesmo. Por esse motivo, deve-se ter cuidado, ao fazer generalizações e ao usar imagens, uma vez que elas podem conduzir a erros e a enganos na compreensão de teorias.

A análise da história e da construção das Geometrias não Euclidianas permite a observação de que, ao longo de quase dois mil anos, os matemáticos e as pessoas envolvidas com esses estudos geométricos encontraram obstáculos e resistências que dificultaram a construção e o entendimento das Geometrias não Euclidianas (Boyer, 1999; Eves, 1992). Tem-se por hipótese que essas dificuldades, esses obstáculos também se manifestem nos professores/alunos, quando estudam esses conteúdos.

Dificuldades e obstáculos epistemológicos identificados durante o

Zetetiké - FE/Unicamp - v. 22, n. 42 - jul/dez-2014 
estudo da Geometria Hiperbólica por meio do modelo do disco de Poincaré

Antes de iniciar as atividades com o GeoGebra, apresentou-se uma introdução de alguns resultados da Geometria Hiperbólica, que podem ser observados no Modelo do disco de Poincaré e, por isso, no decorrer deste texto, será assim denominado. Para construir o modelo, este matemático usou elementos da Geometria Euclidiana.

Os pontos desse modelo são pontos no sentido de Euclides. O plano é, por definição, o interior de um círculo euclidiano, ou seja, se $\mathrm{O}$ é o centro de uma circunferência euclidiana qualquer e OR um de seus raios, o plano no modelo hiperbólico é constituído por todos os pontos $\mathrm{P}$ tais que $\overline{\mathrm{OP}}<\overline{\mathrm{OR}}$. A circunferência (que, por definição, não faz parte do plano) é chamada de horizonte.

A reta no modelo do disco de Poincaré, por definição, são as cordas (sem os extremos) que passam pelo centro $\mathrm{O}$, isto é, os diâmetros; e os arcos de circunferências sem os extremos, ortogonais ao horizonte ${ }^{6}$. No decorrer do texto, as retas hiperbólicas serão chamadas de h-retas.

Os pontos de intersecção das retas hiperbólicas com o horizonte, ou seja, os pontos F, G, I e K, na Figura 2, não pertencem ao plano hiperbólico e são chamados de pontos ideais das h-retas AE e CD, respectivamente, e, segundo a definição de métrica definida neste modelo (também discutida no minicurso e apresentada posteriormente neste texto), estão no "infinito".

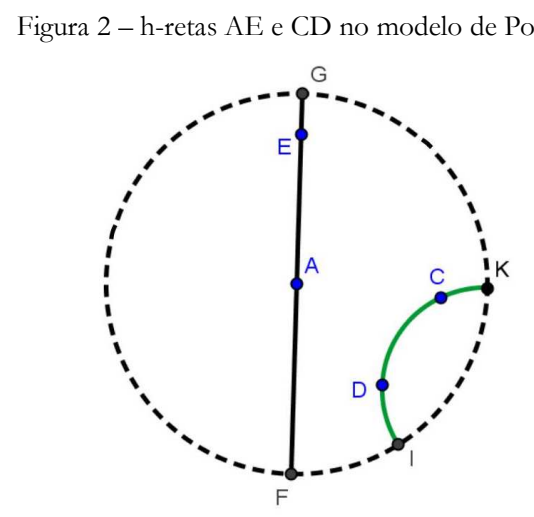

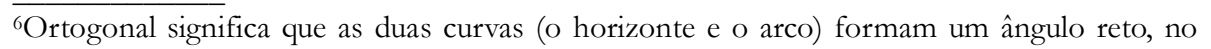
ponto de interseção.

Zetetiké - FE/Unicamp - v. 22, n. 42 - jul/dez-2014 
Fonte: Autores deste texto

Um dos primeiros obstáculos que os professores participantes encontraram foi no entendimento do que é o plano nesse modelo: tiveram dificuldades em compreender que o plano hiperbólico é infinito, tendo em vista que o plano é o interior do círculo euclidiano. Nos trechos que seguem, os ministrantes serão denotados por $\mathrm{M}$, e os professores participantes da pesquisa, por P. M1 questiona os professores sobre a existência do plano hiperbólico:

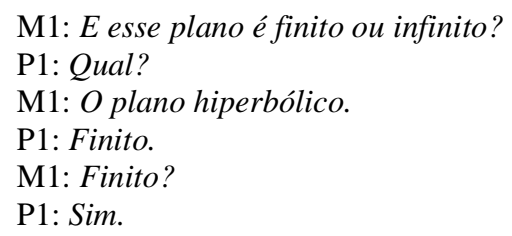

Para o professor P1, o plano hiperbólico, pelo fato de o plano ser o interior do círculo, deve ser limitado e, dessa forma, finito. P1 não atentou para a definição de plano, apontada anteriormente, e baseou-se na representação geométrica apresentada. Além disso, a "nova representação" de plano causou espanto, já que, no modelo de Poincaré, podem-se "ver" os pontos no infinito, o que não acontece na Geometria Euclidiana, por exemplo.

Nesse contexto, destaca-se que os conceitos e as propriedades da Geometria Euclidiana exercem forte influência, quando se tenta mostrar uma nova Geometria. Nesse caso, um conhecimento geral, tido como único e geral, constitui um obstáculo no entendimento de novos conceitos.

Outro obstáculo observado foi em relação às h-retas. A professora P2, após a construção de uma h-reta, ficou em dúvida se o arco construído, ou seja, uma h-reta, era, de fato, ortogonal ao horizonte do plano hiperbólico:

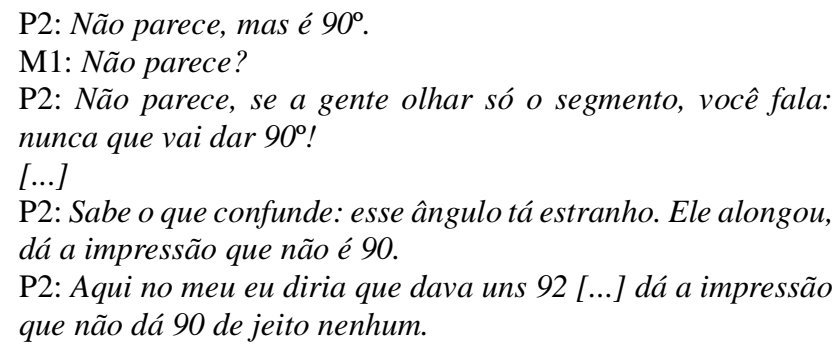

Observa-se a dificuldade de P2 aceitar o fato de o arco ser ortogonal à circunferência. A representação de ortogonalidade não é aquela à qual ela está

$$
\text { Zetetiké - FE/Unicamp - v. 22, n. } 42 \text { - jul/dez-2014 }
$$


habituada, ou seja, um ângulo reto entre duas retas euclidianas. Neste caso, percebe-se que uma "nova representação" se torna um obstáculo verbal: "um caso em que uma única imagem, ou até uma única palavra, constitui toda a explicação" (Bachelard, 1996, p. 91).

$\mathrm{Na}$ sequência, a professora P3 questiona M1 se o objeto construído é uma reta:

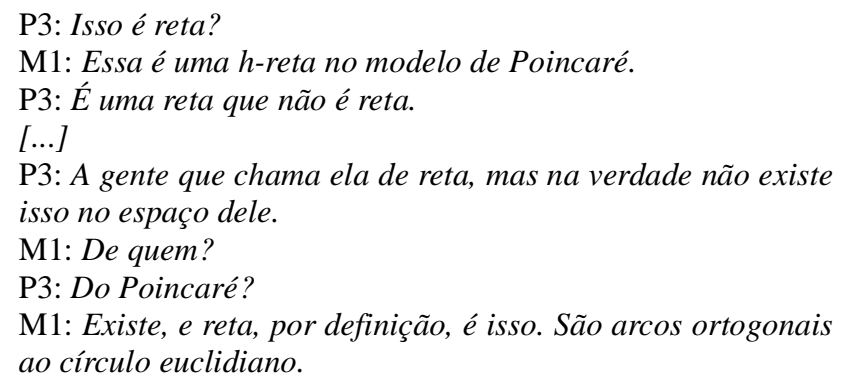

Ao falar que "é uma reta que não é reta", a professora P3 usa a noção de reta do senso comum, ou seja, para ela, a palavra "reta" expressa todo o significado de um objeto geométrico, dificultando o entendimento de que aquele objeto geométrico, um arco da circunferência na Geometria Euclidiana, é uma reta no modelo hiperbólico. Sobre as retas, Poincaré (1995) expõe que,

\footnotetext{
no espaço, conhecemos triângulos retilíneos dos quais a soma dos ângulos é igual a dois ângulos retos; mas conhecemos igualmente triângulos curvilíneos dos quais a soma dos ângulos é menor que dois ângulos retos. A existência de uns não é mais duvidosa que a dos outros. Dar aos lados dos primeiros o nome de retas é adotar a geometria euclidiana; dar aos lados dos últimos o nome de retas é adotar a geometria não euclidiana. Assim, perguntar que geometria convém adotar é perguntar a que linha convém dar o nome de reta (Poincaré, 1995, p. 41).
}

Poincaré (1995) destaca ainda que a experiência não resolve tal questão e que, quando se descreve que a reta euclidiana "é uma reta verdadeira" e a reta não euclidiana "não é uma reta verdadeira", o que se quer dizer é simplesmente que a primeira ideia intuitiva de reta corresponde a um objeto mais notável do que a segunda. No caso da representação de h-retas, observa-se novamente um obstáculo verbal.

O conceito de ângulo entre h-retas também foi apresentado para aos professores. No modelo de Poincaré, quando duas h-retas se interceptam em um ponto, elas formam um ângulo, e a medida desse ângulo é, por definição, a

$$
\text { Zetetiké - FE/Unicamp - v. 22, n. } 42 \text { - jul/dez-2014 }
$$


medida do ângulo formado pelas retas euclidianas que são tangentes aos arcos (h-retas) no ponto em que estes se interceptam, conforme Figura 3.

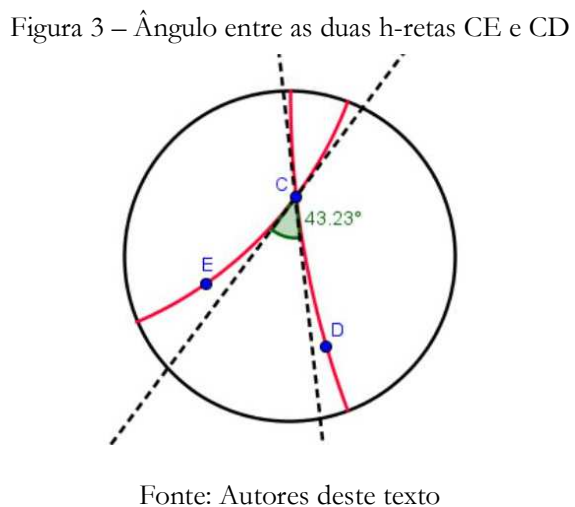

Após a explicação e a apresentação, por meio do GeoGebra, de como encontrar um ângulo entre duas retas no modelo de Poincaré, solicitou-se que os professores encontrassem o ângulo entre duas h-retas. Porém, o que se observou foi que eles realizaram a atividade como se estivessem na Geometria Euclidiana:

M1: Alguém tem alguma ideia de como vai calcular o ângulo? P4: Ângulo.

M1: Eu quero calcular o ângulo formado por essas duas retas hiperbólicas.

P4: Seleciona ângulo. E depois E, C, D.

$\mathrm{M} 1: E, C, D$ ?

P4: É! E, C, D [...] é sentido horário.

[...]

M1: É isso, será? É esse ângulo que eu acabei de calcular?

P5: Esse tem que ser hiperbólico mesmo.

M1: E aqui é o quê?

P5: Euclidiano.

M1: Ele é euclidiano, eu não posso calcular esse ângulo assim.

Mesmo após terem visto a definição de ângulo no modelo de Poincaré, os professores ainda pensavam como se estivessem calculando o ângulo na Geometria Euclidiana. Esse fato evidencia a dificuldade que eles têm em se desprender dos conceitos e das definições dessa Geometria, o que, por seu turno, sinaliza um obstáculo no entendimento de novos conceitos.

Pela necessidade de tornar o segundo postulado da Geometria

$$
\text { Zetetiké - FE/Unicamp - v. 22, n. } 42 \text { - jul/dez-2014 }
$$


Hiperbólica (que coincide com o segundo postulado da Geometria Euclidiana) verdadeiro, Poincaré definiu uma métrica em seu modelo. A distância entre dois pontos A e B, no modelo explorado é, por definição, dada pela seguinte equação: $d(\mathrm{~A}, B)=\left|\ln \frac{\overline{\mathrm{AU}} * \overline{\mathrm{BV}}}{\overline{\mathrm{AV}} * \overline{\mathrm{BU}}}\right|$, na qual $\mathrm{U}$ e $\mathrm{V}$ são pontos ideais da h-reta $\mathrm{AB}$. A operação definida por * é a multiplicação usual de números reais, e as medidas $\overline{\mathrm{AU}}, \overline{\mathrm{BV}}, \overline{\mathrm{AV}}$ e $\overline{\mathrm{BU}}$ são as medidas dos segmentos euclidianos $\mathrm{AU}, \mathrm{BV}, \mathrm{AV}$ e $\mathrm{BU}$, respectivamente.

Poincaré usou essa métrica para construir um plano infinito (plano hiperbólico), em um espaço limitado (círculo euclidiano). Note-se que a métrica construída por Poincaré permite que, quando os pontos A e B se aproximarem dos pontos ideais, o valor das medidas $\overline{\mathrm{AV}}$ e $\overline{\mathrm{BU}}$ diminui e, consequentemente, o logaritmando aumenta. Assim, a função distância tende ao infinito. Quando os pontos A e B se aproximam, o valor das medidas $\overline{\mathrm{AU}}$ e $\overline{\mathrm{BV}}$ se aproxima das medidas de $\overline{\mathrm{AV}}$ e $\overline{\mathrm{BU}}$ e, dessa forma, o logaritmando tende ao número 1, o que ocasiona, depois da aplicação da função logarítmica, uma distância que tende a zero.

Quando questionados sobre como é calculada a distância entre dois pontos nesta Geometria, o professor P3 sugeriu:

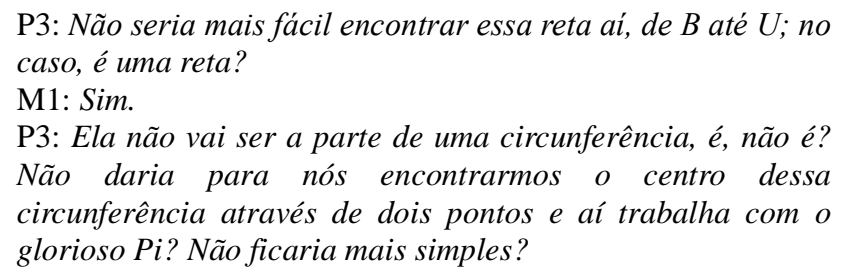

O professor P3 questiona M1 se não seria possível encontrar a distância usando a ideia do comprimento de um arco. Nesse momento, evidencia-se a dificuldade dos professores em compreender que o arco de circunferência representado é uma h-reta. Para o professor P3, esse arco era um arco euclidiano e seria perfeitamente possível calcular o comprimento do arco para saber a distância entre os pontos A e B. Percebe-se que existe uma "contaminação" pela representação e pelos conceitos da Geometria Euclidiana, o que, neste caso, indica um obstáculo epistemológico - conhecimento geral no entendimento da Geometria Hiperbólica.

Após estudar os ângulos no modelo de Poincaré, passou-se para a análise das retas paralelas nesse modelo, as quais, assim como na Geometria

$$
\text { Zetetiké - FE/Unicamp - v. 22, n. } 42 \text { - jul/dez-2014 }
$$


Euclidiana, não possuem qualquer ponto em comum. Os professores construíram algumas h-retas e, depois, foram questionados sobre quais e quantas eram as paralelas. $\mathrm{Na}$ Figura 4, a seguir, apresentam-se algumas h-retas:

Figura 4 - h-retas paralelas

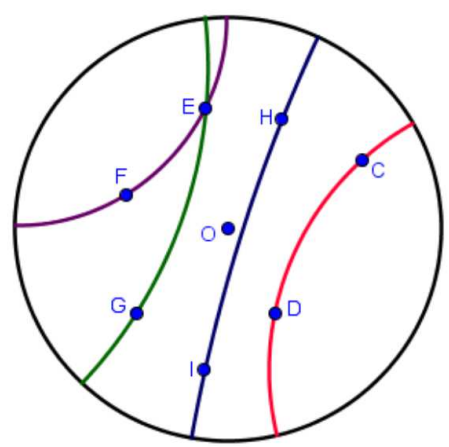

Fonte: Autores deste texto

M1: Quem que é paralela a quem ai?

P4: Quem que é paralela?

M1: E.

P4: É sempre o [...] essa aqui é paralela a essa, essa é paralela a essa (a professora mostra com quais retas são paralelas).

M1: Isso [...] essa aqui é uma paralela, essa, essa [...] já tem três.

P4: Tem bastante, né?

M1: Infinitas?

P4: Infinitas retas paralelas.

M1: O que na euclidiana não acontece.

P4: É, lá ele diz que só tem uma reta paralela.

$\mathrm{Na}$ Figura 4, as h-retas EF e EG passam pelo ponto E e são paralelas à h-reta $\mathrm{CD}$. Ainda nessa figura, a h-reta $\mathrm{HI}$ também é paralela à h-reta $\mathrm{CD}$. A maioria dos professores não teve dificuldades em observar as retas paralelas no modelo de Poincaré. Quando questionada sobre quais retas eram paralelas, a professora P4 surpreendeu-se com a quantidade de retas que encontrou.

Por fim, construiu-se um triângulo hiperbólico (ver Figura 5) e questionou-se qual deveria ser a soma das medidas dos ângulos internos. Nesse momento, alguns responderam que a soma era menor do que $180^{\circ}$, outros responderam que não era, e houve ainda aqueles que ficaram em dúvida. Como 
os professores não estavam convencidos de que a soma das medidas dos ângulos internos de um triângulo hiperbólico fosse menor do que $180^{\circ}$, solicitou-se que eles encontrassem os ângulos e, posteriormente, calculassem a soma dos ângulos internos, a fim de verificar qual era o valor.

Figura 5 - Triângulo hiperbólico ABC

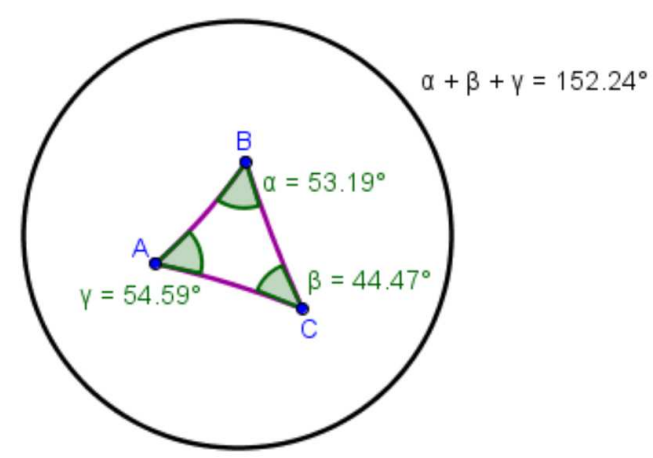

Fonte: Autores deste texto

No diálogo a seguir, M1 questiona os professores a respeito da soma dos ângulos internos de um triângulo:

M1: A soma dos ângulos que vocês calcularam ai é maior, menor ou igual a $180^{\circ}$ ?

P5: Menor.

P6: Acho que é menor.

M1: Vamos calcular pra ver quanto que deu.

[...]

M1: Achou o 180?

P5: 179.1.

M1: Será que chega até 180?

P5: Não, eu sei que não chega.

No diálogo acima, os professores P5 e P6 discutem com M1 se a soma das medidas dos ângulos internos do triângulo é menor que $180^{\circ}$ e se pode ser igual a esse valor. Depois de movimentar os vértices do triângulo, P5 observa que não é possível obter um triângulo cuja soma das medidas dos seus ângulos internos seja igual a $180^{\circ}$.

Durante o minicurso, os professores apresentaram dificuldades, inclusive, com os conceitos da Geometria Euclidiana, a saber: nos casos de congruência e semelhança de triângulos; nas noções de retas, semirretas, 
segmentos de retas; nas propriedades das retas tangentes e paralelas; na definição de ângulos e ângulos entre retas; e nas construções geométricas. Acredita-se que esse fato tenha dificultado o entendimento e a aceitação da Geometria Hiperbólica.

\section{Considerações}

O estudo do modelo do disco de Poincaré permitiu identificar algumas dificuldades e obstáculos que impedem a compreensão dos conceitos da Geometria Hiperbólica. Acredita-se que uma das causas tenha sido, principalmente, o fato de os professores acreditarem que as representações dos objetos geométricos sejam, de fato, o próprio objeto, como aconteceu no caso da h-reta. Outro motivo que dificultou o entendimento do modelo exposto foi o fato de a maioria dos professores acreditar que a Geometria Euclidiana é a única Geometria possível. Também se destaca o desconhecimento de alguns conceitos e resultados da própria Geometria Euclidiana.

$\mathrm{O}$ fato de a maioria dos professores conhecer somente a Geometria Euclidiana e acreditar que ela é a única possível tornou-se um obstáculo denominado de "conhecimento geral". Observou-se ainda que os professores tiveram dificuldades em abandonar os conceitos e as definições da Geometria Euclidiana, como um conhecimento geral.

Destaca-se que as representações de retas, triângulos, retas paralelas, ângulos, etc., na Geometria Hiperbólica, são diferentes da Geometria Euclidiana. Os professores estão familiarizados com as representações euclidianas, e uma "nova representação" apontou um obstáculo verbal: "um caso em que uma única imagem, ou até uma única palavra, constitui toda a explicação" (Bachelard, 1996, p. 91).

O uso de palavras que se acredita expressarem toda explicação do objeto geométrico também permitiu identificar um obstáculo verbal. Nesse caso, os professores usaram o entendimento da palavra "reta", por exemplo, do senso comum, ou seja, qual reta deve ser um "objeto geométrico reto".

Acredita-se que, para compreender as Geometrias não Euclidianas, o professor terá que romper com a ideia de conhecimento geral, uma vez que "o progresso do espírito científico se faz por rupturas com o senso comum, com as opiniões primeiras ou as pré-noções de nossa filosofia espontânea" (Japiassú, 1986, p. 70).

O fato de os professores terem participado do minicurso não garante a compreensão e a aceitação das Geometrias não Euclidianas. Salienta-se que,

$$
\text { Zetetiké - FE/Unicamp - v. 22, n. } 42 \text { - jul/dez-2014 }
$$


para superar os obstáculos e as dificuldades, será necessária uma formação continuada adequada, na qual o professor possa rever e aprender novos conteúdos e metodologias.

\section{Referências}

ANDRADE, D. A. A importância dos obstáculos epistemológicos para o desenvolvimento da ciência: a contribuição de Gaston Bachelard. Pensar, Fortaleza, v. 9, p. 45-49, 2004.

BACHELARD, G. A formação do espírito científico. Tradução de Estela dos S. Abreu. 3. reimp. Rio de Janeiro: Contraponto, 1996.

BARKER, S. F. Filosofia da Matemática. Tradução de Leonidas Hegenberg e Octanny S. da Mota. Rio de Janeiro: Zahar, 1969.

BOYER, C. História da Matemática. Tradução de Elza F. Gomide. 2. ed. São Paulo: Edgard Blucher, 1999.

EUCLIDES. Os elementos. Tradução de Irineu Bicudo. São Paulo: Editora Unesp, 2009.

EVES, H. História da Geometria. Tradução de Hygino H. Domingues. São Paulo: Atual, 1992. GÁLVEZ, D. A geometria, a psicogênese das noções espaciais e o ensino da geometria na escola primária. In: SAIZ, C. P. I. (Org.). Didática da Matemática. São Paulo: Artmed, 2006.

GEOGEBRA. Software. Disponível em: <http://www.geogebra.org>. Acesso em: 24 fev. 2014.

GERDES, P. Sobre o despertar do pensamento geométrico. Curitiba: Editora da UFPR, 1992. JAPIASSÚ, H. Introdução ao pensamento epistemológico. 4. ed. Rio de Janeiro: Francisco Alves, 1986.

PARANÁ. Secretaria de Estado da Educação. Diretrizes Curriculares de Matemática para a Educação Básica. Curitiba, 2008.

PIAGET, J.; GARCIA, R. Psicogénese e história das ciências. Tradução de Maria

Fernanda de M. R. Jesuíno. Lisboa: Dom Quixote, 1987.

POINCARÉ, H. Ensaios fundamentais. Tradução de Vera Ribeiro. Rio de Janeiro: Contraponto; PUC Rio, 2008.

POINCARÉ, H. O valor da ciência. Tradução de Maria Helena F. Martins. Rio de Janeiro: Contraponto, 1995.

SANTOS, T. S. A inclusão das geometrias não-euclidianas no currículo da Educação Básica. Dissertação (Mestrado) - Programa de Pós-Graduação em Educação para a Ciência e a Matemática. Universidade Estadual de Maringá, Maringá, 2009. 138f.

SOUZA, J. C. de M. O escândalo da Geometria. Rio de Janeiro: Aurora, 1948.

TROVON, A. Obstáculos epistemológicos e didáticos. Disponível em: <http://people.ufpr.br/ trovon/cursos/2012_Especializacao/obstaculos.pdf>. Acesso em: 24 fev. 2014.

Submetido em 20/01/2012

Aprovado em 11/02/2014 